\title{
Achieving Social and Ecological Outcomes in Collaborative Environmental Governance: Good Examples from Swedish Moose Management
}

\author{
Sabrina Dressel ${ }^{1, *(\mathbb{D}}$, Annelie Sjölander-Lindqvist ${ }^{2} \mathbb{D}$, Maria Johansson ${ }^{3}$, Göran Ericsson ${ }^{1}$ \\ and Camilla Sandström ${ }^{4}$ (D) \\ 1 Department of Wildlife, Fish \& Environmental Studies, Swedish University of Agricultural Sciences, \\ SE-90183 Umeå, Sweden; goran.ericsson@slu.se \\ 2 School of Global Studies \& Gothenburg Research Institute (GRI), University of Gothenburg, \\ SE-40530 Gothenburg, Sweden; annelie.sjolander-lindqvist@gu.se \\ 3 Environmental Psychology, Department of Architecture and the Built Environment, Lund University, \\ SE-22100 Lund, Sweden; maria.johansson@arkitektur.lth.se \\ 4 Department of Political Science, Umeå University, SE-90187 Umeå, Sweden; camilla.sandstrom@umu.se \\ * Correspondence: Sabrina.Dressel@slu.se; Tel.: +46-90-786-8558
}

\section{check for}

updates

Citation: Dressel, S.;

Sjölander-Lindqvist, A.;

Johansson, M.; Ericsson, G.;

Sandström, C. Achieving Social and

Ecological Outcomes in Collaborative

Environmental Governance: Good

Examples from Swedish Moose

Management. Sustainability 2021, 13,

2329. https://doi.org/10.3390/su

13042329

Academic Editor: Tasos Hovardas

Received: 22 December 2020

Accepted: 11 February 2021

Published: 21 February 2021

Publisher's Note: MDPI stays neutral with regard to jurisdictional claims in published maps and institutional affiliations.

Copyright: (c) 2021 by the authors. Licensee MDPI, Basel, Switzerland. This article is an open access article distributed under the terms and conditions of the Creative Commons Attribution (CC BY) license (https:// creativecommons.org/licenses/by/ $4.0 /)$.

\begin{abstract}
Collaborative governance approaches have been suggested as strategies to handle wicked environmental problems. Evaluations have found promising examples of effective natural resource governance, but also highlighted the importance of social-ecological context and institutional design. The aim of this study was to identify factors that contribute to the achievement of social and ecological sustainability within Swedish moose (Alces alces) management. In 2012, a multi-level collaborative governance regime was implemented to decrease conflicts among stakeholders. We carried out semi-structured interviews with six 'good examples' (i.e., Moose Management Groups that showed positive social and ecological outcomes). We found that 'good examples' collectively identified existing knowledge gaps and management challenges and used their discretionary power to develop procedural arrangements that are adapted to the social-ecological context, their theory of change, and attributes of local actors. This contributed to the creation of bridging social capital and principled engagement across governance levels. Thus, our results indicate the existence of higher-order social learning as well as a positive feedback from within-level collaboration dynamics to between-level collaboration. Furthermore, our study illustrates the importance of institutional flexibility to utilize the existing knowledge across stakeholder groups and to allow for adaptations based on the social learning process.
\end{abstract}

Keywords: adaptive management; collaborative governance regime; collaboration dynamics; institutional flexibility; leadership; multi-level governance; social capital; social learning

\section{Introduction}

There have been major changes in Swedish wildlife populations and their management during the last century. Due to factors including overexploitation and sparse regulations, many populations were low at the start of the 20th century [1,2]. However, a subsequent focus on conservation and stricter harvest regulations, in combination with changes in land use practices, led to the recovery of many species [2-4]. Moose (Alces alces) is a figurehead of this development and one of the most valued huntable species in Sweden [2,5]. Its population has dramatically recovered from a few thousand individuals in the early 20th century to an estimated 400,000 in 1980 [1,4]. This rapid increase in population was accompanied by negative impacts on the forestry sector and conflicts between stakeholders $[1,4]$, largely because Scots pine (Pinus sylvestris) is both a commercially important tree species and a preferred forage resource for moose [6,7]. Thus, forestry and hunting stakeholders have conflicting interests, which require collective resolution. 
Various management approaches tested over time failed to handle the growing conflicts between forestry and hunting interests [2-4]. In 2009, the governance system was described as lacking a holistic perspective and ability to control moose browsing pressure and moose-car collisions effectively $[8,9]$. As a result of the identified shortcomings, and in line with Sweden's commitment to implement an ecosystem approach according to the Malawi principles [10], the existing policy was amended [11]. The resulting system can be described as a multi-level collaborative governance regime (CGR), in which decisionmaking and the spatial scale of governance have been adapted to the ecosystem in the form of Moose Management Areas (MMA). Furthermore, collaboration has been emphasized as the central tool to address the interdependence of interests and enhance the participation of forest owners and hunters in efforts to collectively resolve existing conflicts. This is consistent with a general turn to collaborative environmental governance models through which people across the boundaries of public agencies, levels of government, and/or the public, private and civic spheres contribute to policy decision-making and management of natural resources [12-15].

In our case, the overarching goals of the introduction of the CGR are to maintain a high-quality moose population while reducing browsing damage, traffic accidents and the conflicts that arise when different interests clash [11]. The multi-level design is intended to allow for locally adapted management strategies while safeguarding the achievement of regional and national goals regarding moose population levels and reducing browsing damage. The amended policy highlights the importance of collaboration to achieve the goals, but it does not explicitly specify how collaborative processes should be implemented [11]. This has partially led to uncertainty about their implementation [16] and roles of different governance levels [17]. Additionally, County Administrative Boards (CABs), which are responsible for the state administration in their respective counties, are independent from the government, which gives them certain discretion regarding policy implementation. In the case of the amended moose policy, this has led to diversity in how the new 'ecosystem level' was defined and numbers of MMAs per county, which ranges between 2 and 16 [18]. As a consequence of this discretion in implementation, there is no systematic overview of the exact institutional arrangements for multi-level collaboration and goal alignment within the CGR. Recent attempts by the Swedish Environmental Protection Agency to evaluate the CGR have identified limitations in its outcomes. More precisely, their evaluations report shortcomings regarding achievement of the overarching aims of the moose policy in terms of harvest quota fulfilment and reduction of browsing damage $[19,20]$.

This illustrates a common knowledge gap regarding CGRs. While collaborative forms of environmental governance have gained much attention from policymakers, practitioners and researchers in recent decades, central questions concerning the links between design, implementation and effectiveness are still unanswered [15,21-24]. Previous research has highlighted that there are no blueprint solutions and needs for governance regimes to acknowledge the social-ecological context (e.g., size and productivity of the resource system, number of actors and existing norms), and design institutions accordingly [14,25]. Knowledge of the dynamics and outcomes of environmental collaborative governance must therefore be understood in relation to the context setting [12,22,26].

The social-ecological context has also been identified as an important factor in the Swedish moose management case. Our previous research efforts have revealed direct effects of context variables (i.e., area size, land use diversity, presence of other ungulate species and fluctuations in forage availability) on collaboration dynamics and quota fulfilment [27]. They also illustrate the social-ecological variability in the context to which the system must be adapted [18]. Thus, a high adaptive capacity of institutions and involved actors as well as social learning will be needed to adjust the CGR. The perceived adaptive capacity of actors has been shown to depend on multi-level collaboration, or more precisely, the presence of linking and bridging social capital among governance levels [28]. Furthermore, the time that actors invest in collaborative activities and the building of collectively shared knowledge within management groups also contributes to goal fulfilment [27]. Thus, multi- 
level collaboration dynamics play a critical role within the system, and we suggest that it is essential to understand central elements of good collaboration, both within and among levels. This, we argue, will provide important insights into the practical realm of multilevel CGRs. In line with this, and as part of a government assignment (N2018/04160/FJR), the objective of the study reported here was to identify and characterize 'good examples' within the CGR. We define 'good examples' as groups that achieved positive social and ecological outcomes. Studying these cases may provide concrete practical insights into working procedures that can be adapted by other actors in the system. It can also contribute to the theoretical understanding of collaboration dynamics in multi-level settings, thereby facilitating establishment of more sustainable approaches in the management of common resources, and avoidance of problematic measures [29].

\subsection{Analytical Framework}

Collaborative governance has been advocated as a strategy for handling 'wicked problems' associated with high levels of societal complexity that pose difficulties for authorities to carry out their tasks [12,30,31]. Generally, benefits include increases in legitimacy, participation, effectiveness and sustainability $[15,21,23,32]$. This frequently touted strategy mirrors the understanding that without integration of sufficient variety of actors, each with unique perspectives and knowledge, it will be difficult to find solutions to commonly identified problems [33]. Thus, the establishment of a CGR in our case can be conceptualized as the formation of a new forum for social interaction and learning regarding wildlife management (cf. Reference [34]), and reconciliation of the needs of the forestry and hunting sectors to implement an ecosystem approach according to the Malawi principles. This implies that the effectiveness of the CGR cannot be determined by only considering the environmental outcomes (e.g., levels of browsing damage). Social processes, such as the integration of involved actors' perspectives and knowledge, as well as the alignment of their interests, are equally important aspects $[35,36]$. To fully assess a system's sustainability, social outcomes such as social learning, increased legitimacy and trust building should be considered alongside ecological outcomes [13]. Inter alia, the dynamics of concrete situations of collaborative governance where processes, actions, output and outcomes are dealt with must be explored and compared [12,37].

Our analytical framework for exploring the collaboration dynamics within and between levels is based on the Integrative Framework for Collaborative Governance (IFCG; [12]). The IFCG consists of a set of nested dimensions of the system context surrounding the CGR and the collaboration dynamics, thereby setting the political, legal and socio-cultural frame for interaction (Figure 1). Collaboration dynamics, as the central part within the CGR, generate outputs and collective action to achieve desired outcomes [12]. Collaboration dynamics can be understood as a virtuous cycle of principled engagement, shared motivation and capacity for joint action (see Figure 1). These elements and their components foster each other in an iterative manner [12]. Through the collaboration dynamics, actors develop a common purpose, a set of goals and a shared theory of change to achieve these goals. Outputs of collaboration dynamics can be agreements, plans and collaborative actions, which are intended to create desired outcomes [32]. Outcomes may refer to ecological aspects (e.g., the condition of a natural resource), as well as social or political attributes (e.g., perceived legitimacy of the regime), and their definition depends largely on the context [12]. Feedback from outcomes can lead to adaptations of actions but also influence collaboration dynamics. Thus, collaboration dynamics evolve over time in response to internal or external changes. Adaptation of collaboration dynamics can be understood as a measure for improving the process performance of the CGR [32,38] and an indicator for higher-order social learning [29], as actors are adjusting their actions to increase effectivity. Collaboration dynamics are the central focus of this study; therefore, a more detailed operationalization of its three elements has been used to analyze the processes, relationships and functional assets of 'good examples' (Figure 1). 


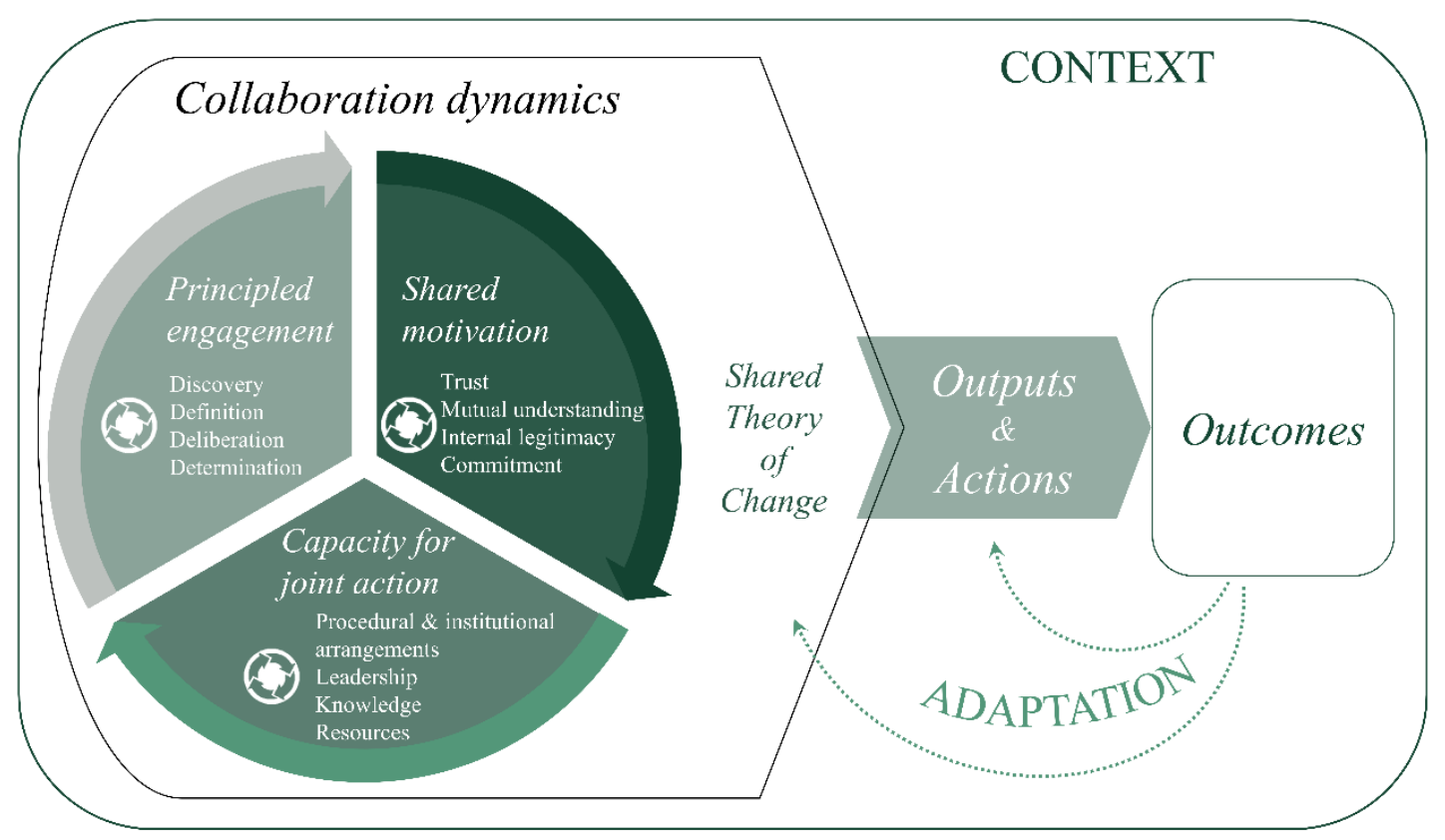

Figure 1. Overview of the analytical framework used to analyze collaboration dynamics within 'good examples' of the collaborative governance regime. Adapted from Emerson and Nabatchi [12].

Following Emerson and Nabatchi [12], principled engagement refers to behavioral interactions of participants in four phases of collective processes: the discovery, definition, deliberation upon and determination of a common understanding and plan of action (Figure 1). CGRs are often implemented in settings with a history of conflict and ongoing struggles to achieve collective action [21]. Thus, as part of the collaboration dynamics and to create effective engagement, differences in understandings and ideas of participants need to be initially explored in order to create collectively acceptable definitions of problems and possible solutions. This lays the groundwork for problem-solving deliberations and clear communication among participants [39]. The process aspects of deliberation must be crafted in a manner that allows balanced and diverse inputs and possibly use of conflict mitigation techniques. During the deliberation process, a myriad of smaller determinations are made along the way to build the final output of the deliberation process. Through the four phases of principled engagement, collaboration participants may be able to create a shared theory of change, which they see as a way to achieve desired outcomes [12]. The process through which shared objectives evolve is similar to 'social or collaborative learning', in which a theory of change is tested and refined over time [14,29,40]. Indicators of principled engagement may include recognition of shared goals and evaluation criteria, reasoned discussion including conflict-solving mechanisms and explicit agreement on a common purpose [12] (p. 192).

Shared motivation refers to relations among participants that incorporate trust, mutual understanding, internal legitimacy and commitment to the group and the process [12] (Figure 1). These components of collaboration dynamics overlap with several dimensions of social capital, and its strong focus on trust [41,42]. Social trust can serve many functions within collaboration dynamics and is reportedly beneficial for efficiency and endurance [43,44]. As a substantial element of social capital, trust can create norms of reciprocity and increase access to resources and knowledge for both individuals and a whole group [43,45]. A mutual understanding of the different values and needs among participants can help to create internal legitimacy and highlight compatibility between individual interests [44]. This can help the participants tie relational bonds and create a feeling of commitment towards the CGR. Emerson and Nabatchi [12] theorize that shared motivation originates from principled engagement but can also have positive feedback to it, as increases in trust can facilitate deliberation among participants. Relevant indicators of shared motivation are the level of trust among 
participants, their capability to identify and respect differences, the level of appreciation among them and the extent that they find participation useful and are committed to the collective purpose [12] (p. 194).

Capacity for joint action relates to the functional assets required to enable the CGR, namely institutional arrangements, leadership, resources and knowledge [12] (Figure 1). While certain procedural arrangements might be drafted during the initiation of a CGR, many formal and informal rules have to emerge over time to guide the collaboration dynamics and enable durable principled engagement. Similarly, initiating leadership has been identified as a central driver that can boost the implementation of a CGR [12] (p. 47). Initiating leaders show capacity to motivate key stakeholders to commit to and invest effort in the collaborative endeavor. Besides the initiating role, other types of leadership such as champions, sponsors, conveners, facilitators/moderators and experts may evolve during the collaboration dynamics and fulfil diverse functions [38]. The types of leadership that emerge might depend on context-specific demands or skillsets of involved participants. A central idea of collaboration is to maximize the utility of individual-based knowledge and resources (e.g., expertise), as they can often be limiting factors for collective action. Thus, joint knowledge generation and information sharing among participants are important assets, which can be supported by structural aspects of engagement and social capital within the CGR. Relevant indicators of the capacity for joint action are: the nature and quality of operational rules, presence of types of leadership, availability, development and sharing among actors of pertinent knowledge and technology, funding, administrative support and expertise [12] (p. 195).

Despite the operationalization of the three elements of collaboration dynamics within the IFCG, there are still gaps in knowledge of their formation and interactions [12] (p. 224), which our study is intended to address. Furthermore, while the IFCG acknowledges that there are links between participants in the collaboration dynamics and their 'parent organization', it does not incorporate aspects of multi-level collaborative governance, which we see as a possible limitation. The implementation of a CGR often spans multiple administrative and governance levels, thereby creating a need for multi-level collaboration [33,43]. Thus, in addition to contributing to understanding of practical aspects of CGRs, our analysis is intended to initiate theoretical discussions regarding multi-level collaboration. More specifically, we aim to explore how collaboration dynamics within a level can influence collaboration dynamics among levels. Relevant indicators of multi-level collaboration may include both formal and informal links between the levels, which can be expressed in terms of procedures for knowledge generation or information-sharing networks between actors and personal connections [35].

\subsection{Study Context}

The implementation of the CGR for moose was externally directed by the Swedish government after it had identified shortcomings in the effectiveness of the previous management system $[8,11]$. Collaborative elements have a long tradition in Swedish wildlife governance [2,27]. Thus, the design of the CGR was partly based on existing administrative and collaborative structures, such as CABs and Wildlife Management Delegations (WMDs) at the regional level (Figure 2). In each of the 20 counties with moose populations, the CABs are responsible for the rule of law and administration of the system, such as officially approving management plans and registering management areas. They are assisted by the WMDs, which are composed of 15-19 representatives of relevant land use and public interest groups tasked with collaboratively deciding strategies and/or goals for various regional wildlife issues, including moose management (Swedish Government Bill 2008/09:2010). Within the design of the CGR, a new 'ecosystem' governance level was created (Figure 2). It consists of 145 MMAs, which are supposed to include $80 \%$ of a distinct moose population. MMAs are led by a Moose Management Group (MMG), which includes three representatives of landowner interests and three representatives of hunting interests. One of the landowner representatives serve as the chairperson and has a casting vote in 
case of a tie. The MMGs collaboratively establish management goals and plans that are adapted to their respective areas. Within these areas, actors can either voluntarily form Moose Management Units (MMUs), which allows them to set-up local management goals and plans, or register as License areas and receive a yearly hunting quota (Figure 2). The MMUs are collaborative forums that were introduced in 1992 [46], but with the amended policy, they have extended possibilities to manage their local moose populations as an incentive to create these voluntary forums. At the time of the survey and interviews this study is based upon, there were 979 MMUs and 2897 License areas, which illustrates the intricacy of the system.

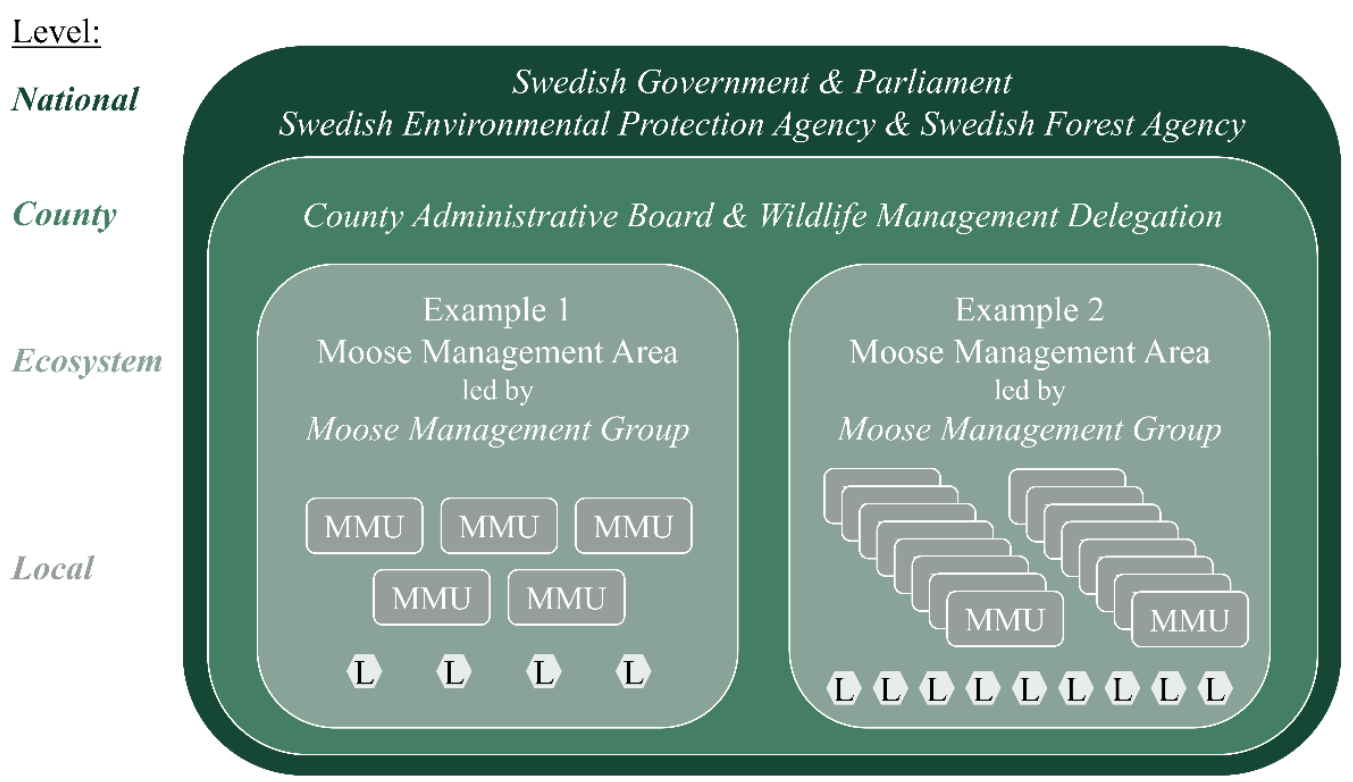

Figure 2. Systematic overview of the nested institutional design of the collaborative governance regime from the national to local governance level. Two Moose Management Areas (MMA) are portrayed as examples to illustrate the variability in numbers of Moose Management Units (MMU) and License areas (L) within MMAs.

The new CGR has created strong interdependency between governance levels as actors at each level (national, county, ecosystem and local) formulate goals and management plans. These should be aligned, which requires collaboration both horizontally and vertically. At the same time, the system combines formal (i.e., WMD and MMA) and voluntary (i.e., MMU) collaborative arenas, which creates additional challenges for multi-level collaboration. While numbers of mandates in the MMGs are regulated, the formation of MMUs is voluntary and incentive-based. This situation creates structural variety in moose management [18]. The number of MMAs per county varies, and their geographical extent can range from 20,000 to more than 2.5 million ha. Numbers of sub-units (i.e., MMUs and License areas) can also vary. While some MMAs consist of a small number of MMUs and License areas, others can have over 100 sub-units (as illustrated in Figure 2, MMA example 1 vs. example 2). These structural differences may influence the collaboration dynamics, possibilities for adaptations and social learning, and ultimately, outcomes of the CGR.

\section{Materials and Methods}

Our previous research efforts have revealed considerable variation in the socialecological context, adaptive capacity and ecological outcomes across the country, and indicated that multi-level collaboration has influenced outcomes of the CGR [18,28,47]. As described above, the newly created Moose Management Areas have a central role in the CGR as they build a link between the formal and informal collaborative arenas, while they should also allow for the adaptation of moose management to the context setting. Thus, we decided to focus on MMGs as the unit of analysis for identifying 'good examples'. 
To explore 'good examples', we deemed a comparative case study approach to be most suitable. The rationale was that this would facilitate analysis and synthesis of the similarities, differences and patterns among multiple cases sharing the common feature of being 'a good example of an MMG'. Thus, it would enable generalization about key issues, such as how and why particular policies or actions work or fail to work [48].

\subsection{Case Selection}

As a first step to select 'good examples', we carried out an online survey to all wildlife managers at the CABs to collect baseline information on the diversity in collaboration dynamics. The questionnaire, administered through the online survey tool Netigate, contained several open-ended questions regarding the governance routines that have been implemented regarding moose management. It also included the direct request to identify "MMAs in which you have both good goal fulfillment and good collaboration" if such exist in the respective county. In December 2018, individualized invitations were sent via email to all 54 wildlife managers. Five respondents informed us that they were not handling moose management issues and two informed us that they had answered collectively with colleagues. After 2 reminders, we received 28 answers (response rate $=60 \%$ ) from wildlife managers at all 20 CABS. We see this as satisfactory, given that our contact list might have included managers who were not actively involved in handling moose administration and thus deemed their colleagues who had responded as more appropriate to answer the questions. The survey identified 15 cases (i.e., MMGs) in 10 counties as potential 'good examples' (Figure 3).

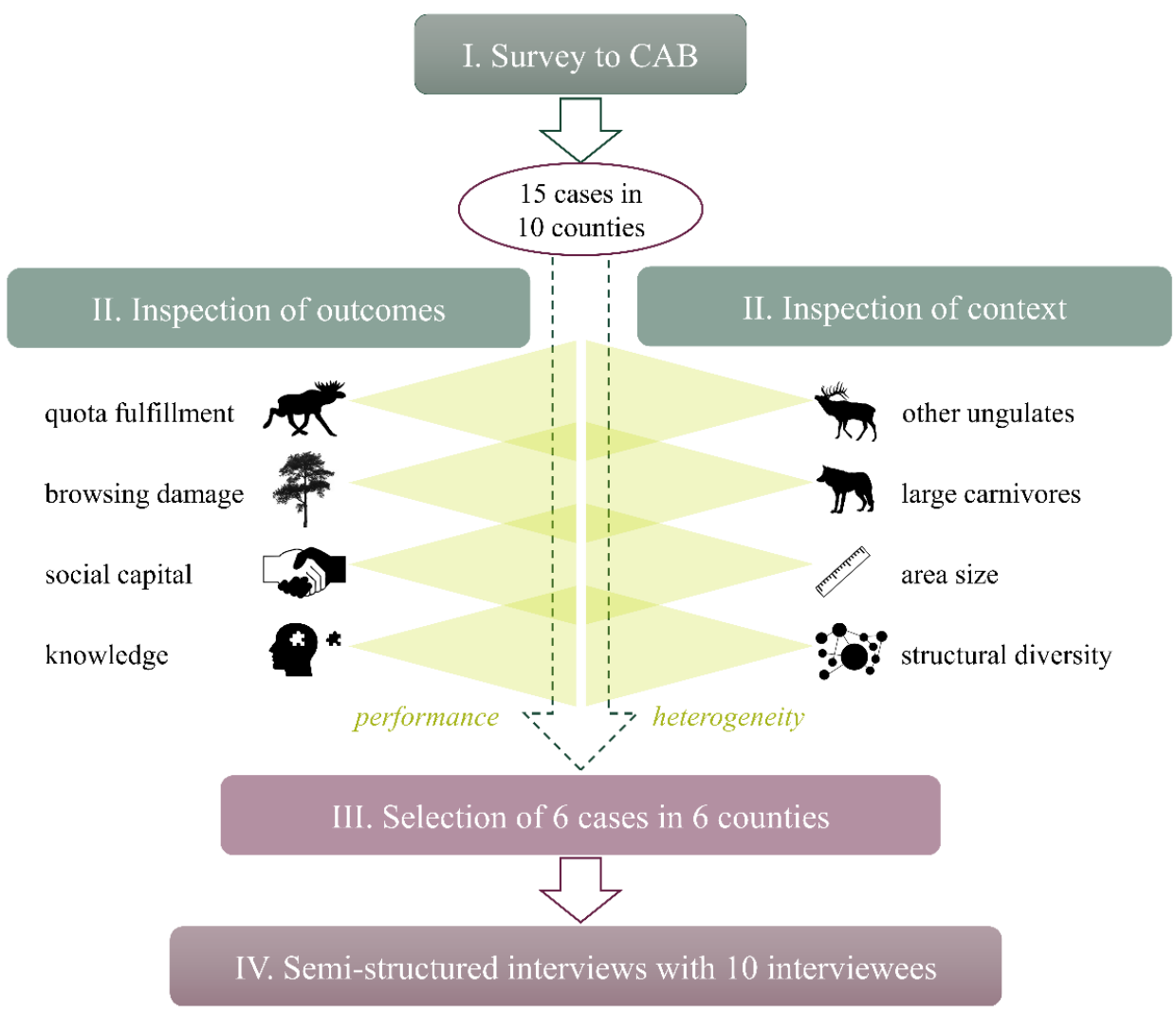

Figure 3. Overview of case selection process to identify 'good examples' within Swedish moose management. Starting with a survey to County Administrative Boards (CAB) that identified potential cases, which were then inspected for good performance regarding outcomes and heterogeneity in context, resulting in the final selection of six cases. The figure illustrates examples of the outcome and context variables that were used within the selection process. 
In the next step, the research team summarized quantitative data on the social and ecological outcomes of these 15 MMGs. In terms of ecological outcomes, this included information on their quota fulfilment between 2014 and 2018, trends in browsing damage in their respective areas and review of their management plans (see Reference [27] for more details on how this data was collected). Concerning social outcomes, a summary of the groups' responses to a survey carried out by the authors in 2016 (described in more detail in Reference [27]) was inspected. Survey data included, for example, measures of bonding social capital (i.e., trust, collaboration and communication within the group), bridging social capital towards MMUs and perceptions of respondents' relevant knowledge of moose management issues. This step showed that most of the named 'good examples' performed better in terms of some or all of these outcome measures than the national average.

Simultaneously, we collected information on the social-ecological context setting of the 15 MMGs. For this, we used context variables that have been highlighted in previous research $[18,27]$, as we wanted to gain a contextualized understanding of how collaboration dynamics in these groups function. Reviewing their management plans gave us insights into the structural diversity of the areas (i.e., number of sub-units), MMA size, the overall goals of the groups (e.g., if they wanted to increase, maintain, or decrease the moose population) and ecological attributes such as presence of other ungulate and large carnivore species, forest conditions and moose densities (Figure 3). We tried to maximize heterogeneity regarding these variables within our MMG selection. The initial information from the survey to CABs in combinations with the data on outcomes and context were used to triangulate which cases would best qualify as 'good examples' (Figure 3). We finally selected six MMGs ranging in location from southern to northern Sweden, thereby including contextual variation in both ecological and social aspects such as land use and landownership. The selected cases are located in the counties Norrbotten, Uppsala, Örebro, Västra Götaland, Jönköping and Kalmar.

\subsection{Recruitment Process and Interviews}

We contacted the chairperson of each selected MMG by email to arrange an interview. As the chairperson is always a landowner representative, we asked for one of the hunter representatives from their group to join as well. All six chairpersons agreed to be interviewed, and four hunter representatives also participated. During March and April 2019, two of the authors collectively elicited views of all of these participants in semi-structured interviews conducted in Swedish, via Skype or phone, lasting on average $60 \mathrm{~min}$. All participants gave informed consent for their comments to be digitally recorded and used in the study. All personal information was handled confidentially, in accordance with the EU's General Data Protection Regulation (2016/679) and ethical research guidelines [49].

The interviews included open-ended questions to let participants describe their area and working process. The order of question themes mirrored the yearly processes that they have to handle within their groups: formulating or revising management plans, collaborating with MMUs in their respective areas, then follow-ups and assistance in quota fulfilment during the hunting season. Furthermore, they were specifically asked about their relations with actors at other governance levels and interest groups, and if they could identify future needs for support from the authorities or research. Thus, the questions allowed exploration of collaboration dynamics within and among governance levels. Throughout the interviews, follow-up questions were used to clarify previous answers or encourage the interviewees to expand responses and/or raise other thoughts or concerns.

The study design was flexible in terms of the final number of included MMGs and we saw the identified six cases as a solid starting point for this explorative study. After six group interviews with 10 interviewees (in two of which no hunter representative participated), both interviewers perceived that saturation was reached and we decided to finish the data collection. While the sample size will not allow for a generalization of the findings, the rich background information and in-depth descriptions of the interviewees 
were deemed sufficient to explore potential patterns among the collaboration dynamics of good examples.

The interviews were fully transcribed and both interviewers took detailed notes during the interview process. The accuracy of the transcripts was checked using the digital recordings. After a preliminary analysis of the material, the interviewees received the original transcripts and a Swedish summary of the researchers' initial conclusions. This gave interviewees a chance to comment on the conclusions and inform us if they felt that something was missing or incorrect. All interviewees were male, due to $95 \%$ of all MMG representatives being male [28] rather than a deliberate study design decision.

\subsection{Thematic Analysis of the Qualitative Data}

A theory-driven thematic coding approach was used to analyze the data. The method is widely used for identifying, analyzing, organizing, describing and reporting themes within a dataset and can be used both deductively and inductively [48]. In this study, we included a mixture of inductive and deductive elements. An initial set of coding themes were defined deductively based on the theoretical framework outlined above, but we allowed additional (sub-)themes to emerge from the empirical material during the analysis process (i.e., inductive coding). Thus, we saw the theory as a tool for exploration with the possibility to refine our understanding of the dynamics between its elements (e.g., which factors contribute to the formation of principled engagement, shared motivation and/or capacity for joint action).

We used QSR International's NVivo 12 software to analyze the material. An iterative process guided the thematic analysis of transcripts, which consisted of multiple rounds in which all of the authors collectively discussed and reviewed the coding. The two authors that also acted as interviewers were responsible for the initial two rounds of coding. First, the material was scanned and ordered according to within-group and among-level references. In the next step, sections were further analyzed according to the broad themes within the theoretical framework (i.e., processes, relational aspects, or functional assets of collaboration dynamics). In round three, another author studied all transcripts and was then included to discuss and revise the existing coding and the interpretation of the findings until consensus was reached. In this step, we also identified commonalities among most or all of the 'good examples' and variations among the six cases. Lastly, the interpretation and example quotes were presented to the remaining author group for further discussion and selection. Translations of quotes used in the findings section were checked by all authors to maximize their validity. Overall, the analysis included multiple recommended processes to increase validity, such as revisiting the material within several coding rounds, sharing preliminary analysis and interpretations with the interviewees, step-wise inclusion of co-authors for internal review and having a research team that has extensive experience in the studied system [50].

\section{Results}

\subsection{Commonalities among 'Good Examples'}

Our analysis showed that across all the selected MMGs, interviewees had extensive previous experience of the subject matter. They were also part of social networks relating to forest and/or wildlife management. Such networks could be within the forest industry, interest organizations or personal connections to local hunting teams. Our interviewees expressed how these social networks had been of help during the start-up of the MMGs. For example, both their extensive experience and social networks assisted them in building relations within the groups. They reported that even if members of the group had not directly worked together before, they knew of one another and their respective backgrounds and expertise. Thus, their experiences could easily feed into the work of the group. Furthermore, the existing social networks of the representatives in the MMGs also helped them to build trustful relationships with the MMUs and hunting teams in their respective areas, and to gain legitimacy. Many of them said that their residential acquaintance with 
the MMA had contributed to the creation of mutual local understanding. Further, their knowledge of the local context helped them create a 'non-bureaucratic' atmosphere. This had given them an essential overview of both important actors and relevant issues to consider in the MMGs.

"... in this area there are many who know each other from before and have an interest in it [relevant management issues]. I don't know what to say about it, but I feel that many have, that we have contacts, maybe not directly meeting each other or being on the same boards, but we still know each other in some way and have an understanding. We were not unknown to each other from the beginning, but in some way, there is someone, we had some contact, and we have a feeling of how things are." (Interview 1, landowner representative)

Experience from similar assignments as elected representatives had also given the interviewees confidence in arranging meetings, guiding deliberation processes and actively representing their respective organizations' interest in these settings. In addition, the ability to draw upon prior experience and knowledge of the focal issues bolstered their security and confidence. The established trust within the groups was expressed in relation to shared responsibilities and appreciation of fellow members' specific expertise, such as specialized knowledge of statistics.

"When it comes to knowledge about monitoring methods, we probably have general knowledge, but of course this is specialized knowledge. But we have X, who is very good at this and can calculate equations by himself without the help of the hunting association and others. It has an effect that we have someone who is very good with this... The rest of us may not have such great knowledge, but it is enough that one has this knowledge and that you can delegate to and trust the one who has the knowledge." (Interview 1, landowner representative)

Many of the interviewed representatives reported that their groups had been stable since their implementation in 2012. There had been few changes in the groups' composition, which according to the interviewees provided stability, because the data, plans, routines and processes were well-known to them all and any deviations would have immediately attracted attention and indicated a need for action. This seemed to create a sense of 'reasonableness', or as one of the interviewees commented: "You get used to looking at these numbers. You get used to seeing where we usually are and you see if things are going in the right direction, if you are used to looking at these numbers. You simply see if it feels reasonable or not." (Interview 5, landowner representative). Above all, this continuity seemed to give the MMG representatives opportunities to develop relationships over time and, together with resultsoriented spirits, build trust and develop mutual understanding of one another's different ways of understanding and approaching the world. This created common understanding and commitment to the group:

"... we are all, so to say, results-oriented people, ... and we have always understood each other's way of being, even though we are so different. And that has done a lot I believe, because we have achieved results quite quickly in our way of working. We don't have, and we don't need to have, confrontations just for the sake of it, but rather we know where we are from the beginning and then we go from there." (Interview 2, landowner representative)

Continuous and open communication within groups was also identified as a common working procedure in all groups, which the interviewees said was important to build good relationships that support contacts outside formal meetings. In this respect, the new system appeared to be superior to the previous system, in which there was limited communication among representatives of different interest groups [3]. Previously, County Administrative Boards mainly carried out goal setting and quota allocation, while the new systems demands that the different interests meet and collaborate to create a common management plan for a MMA. 
In some of the groups, shared motivation and mutual understanding seemed to be favored by the landowner representatives also being hunters, and vice versa. This 'double-identity' was not a characteristic of all the selected groups. However, according to our interviewees, members in the other groups tended to actively focus on the creation of common ground and mutual understanding, for example by inviting each other to meetings of groups they represent, or via socializing activities to get to know one another.

Trust and mutual understanding contributed to the legitimacy within the groups and to a shared sense of commitment to their work, but our interviewees also expressed the importance of supporting one another. For example, they described how the two interests represented in the MMGs collaborated when interacting with actors at other governance levels to show how they made the decisions together. Unity and solidarity were not only important when representing the MMG outwardly, decisions should simply be taken collectively and on equal terms.

“... when we're out visiting the MMUs and participate in their collaboration meetings, or in general when we are acting outwards [of the group], we are always a landowner and a hunter representative together. This simply shows that we have talked with each other before. They can never drive a wedge between us when we're out." (Interview 3, landowner representative)

As they identified this as a strategy to create legitimacy within their groups, they also tried to encourage similar behavioral interactions within their respective MMUs to decrease conflicts between interests. This could be seen as a positive feedback from within-level collaboration dynamics to between-level dynamics. Overcoming the conflicts between the hunters and landowners required the crossing of boundaries, both within and between levels:

"... the landowner side maybe had meetings and we got opportunities to participate from the hunter side, or the other way around so landowners got to know how the hunter side sees things. So, we had an open dialogue all the time really, and did not need to prevaricate or argue about anything, and I believe it was good that it was open. We've also taken this with us to the MMUs and License areas really, so this is how we work the whole time. And I strongly believe that it has become clear to us and them, wherever we've been, $X$ and I and the others, we discovered in different places that this was the way to go." (Interview 2, hunter representative)

Hence, we found in several cases that shared motivation, established within the MMGs, influenced how the groups communicated with actors at other governance levels, above and below the MMG. It appeared to enable them to display unity and encouraged them to attempt to transfer their mutual understanding and commitment to other levels. This was important, as the system was partly introduced because of high levels of conflicts between hunting and landowner interests. Interestingly, we found that these interests were not only reconciling and expressing respect for each other's roles and values but uniting in the understanding that they need to collaborate to overcome obstacles in rural life: "... to be able to live and stay here in the sparsely populated and rural areas together." (Interview 2, hunter representative).

\subsection{Variation among 'Good Examples'}

While the above aspects were common to all or most cases, we also found diversity in terms of collaboration dynamics, including variation in leadership styles, shared theories of change and the procedural and institutional arrangements for the groups' collaboration with the MMUs and License areas (Figure 4). Leadership is considered an essential component of the capacity for joint action, with different types of leadership roles emerging and driving the development of CGRs [12] (p. 72). Theory of change refers to shared assumptions and ideas of what is needed to achieve the commonly agreed goals [12] (p. 64). Thus, it influences the actions and procedures that are implemented in a CGR. 


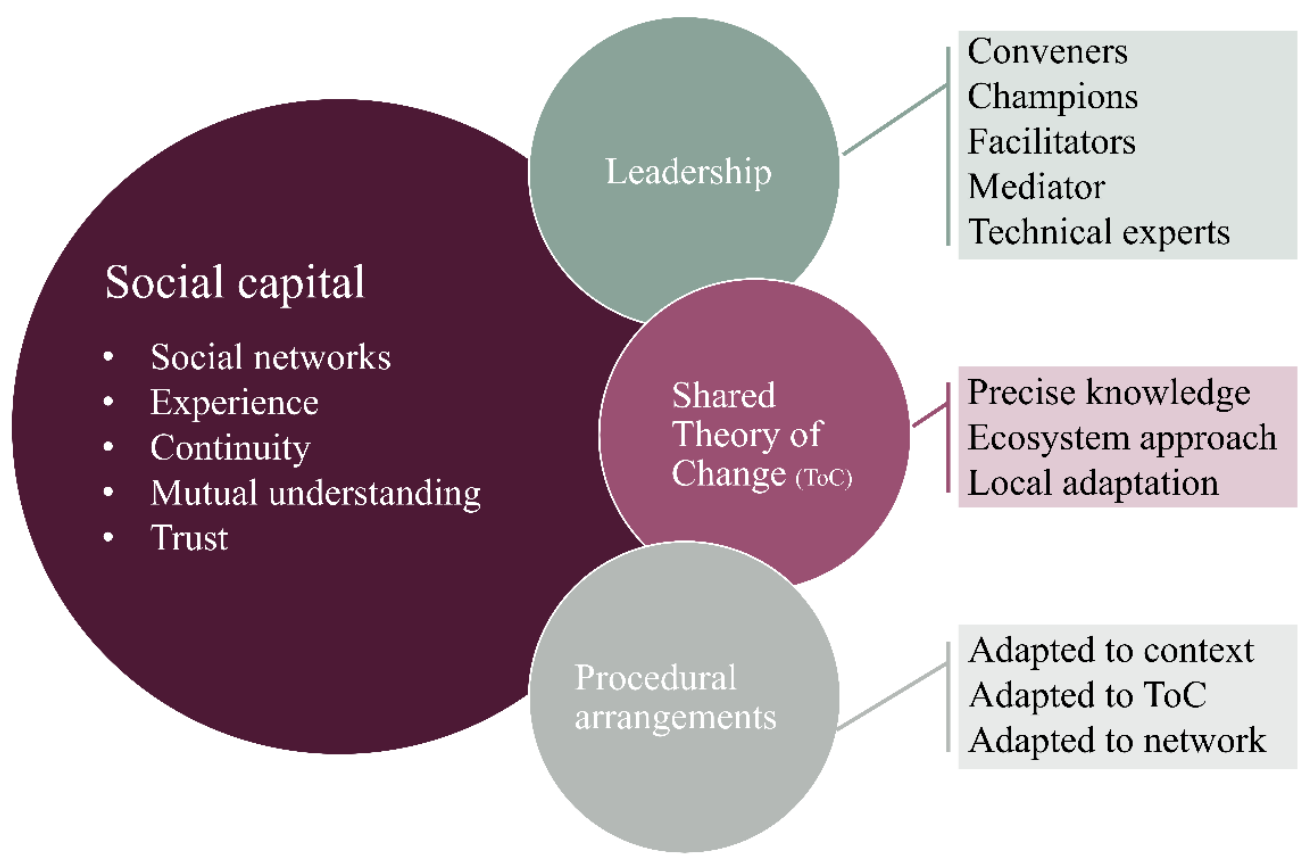

Figure 4. Overview of the main factors contributing to the success of 'good examples'. Social capital was a common feature of all interviewed groups, established via social networks, experience, continuity, mutual understanding and trust. While leadership, a shared theory of change, and procedural arrangements were present in all 'good examples', variations occurred in how these factors were manifested (i.e., different types of leadership styles, theories of change and procedural arrangements).

\subsubsection{Leadership}

Our interviews revealed the presence of different leadership types in the 'good examples' (Figure 4). Some of the interviewees described their role as conveners, that is, they assumed an assisting and balancing role, for example by collecting and presenting information, securing a clear meeting agenda, delegating tasks and cultivating inclusiveness. The MMG leaders who assumed a convening role stressed that they could understand the perspectives of both the hunters and landowners. They had long experience of chairing different kinds of groups and meetings and stressed the importance of providing members of their MMG with functional meeting agendas. This, they said, contributed to focused discussions and provided a way to limit "prattling about hunting". Delegation of tasks was also an important part of their perceived role as chair. It decreased their own burden of work, but also provided, as discussed above, a way of building the group and harnessing the specific competencies of the group members to facilitate their collective activities.

Other chairs could be described as champions, in the sense that they were fully committed to the ideals of the CGR, the aims and mindset of which they tried to spread within and even beyond their areas. They believed in the model and had a long-term perspective, saying that the groups needed to be patient since it "is going to take some time before we see results." (Interview 3, hunter representative). The groups with a 'champion' style of leadership invested much of their time in education and communication with their MMUs and interest groups. Their representatives expressed beliefs that their wide networks and associated relation-building activities (ranging from work-related contacts to engagement with more private- and interest-related groups, such as owners or breeders of hunting dogs) were helpful for creating good relations not only within the MMA, but also with other governance levels. One chair, for example, stated that they "have taken this assignment to try to resolve the issue, and they [MMUs] don't see us as a type of government official, rather that we're there to try to help them so that they can work on this." (Interview 3, hunter representative). The positive recognition they received from other governance levels and a feeling that support was growing further reinforced their role as champions. 
Some of the interviewees saw their role as a facilitator or mediator, understanding that they were called upon by the MMUs to help address conflict situations or assist in organizing and leading meetings:

"We're often invited to consultation meetings out in the Moose Management Units and we often act as chairperson or something, because they think it's nice that there will be outsiders." (Interview 3, landowner representative)

The abilities to listen, be considerate of the characteristic circumstances of different MMUs and be supportive when people want to share their ideas and concerns or ask for help, were held as important for driving dialogue and the decision-making process:

"... we've been available all the time, really, when they run into worries and stuff. We've tried to address it, and things we don't know anything about, we try to find out. So, we try to be very accessible all the time to help them... I feel it's a winning concept then, so you almost don't dare to stop it really, because it works well, really." (Interview 2 , hunter representative)

Lastly, all groups had members that were considered technical experts, which the interviewees explained was very helpful for the analysis and presentation of information, both within the MMGs and externally, for supporting MMUs in formulating their plans.

\subsubsection{Shared Theory of Change}

We discovered that our selection of 'good examples' placed varying emphasis on three central elements of the CGR: decreasing uncertainty by acquiring better (more precise) knowledge, an ecosystem approach and locally adapted management (Figure 4). While management plans and the type of goals that groups determine were similar, interviewees varied in what they identified as the main strategy (i.e., theory of change) to achieve their commonly agreed goals.

Representatives of some of the MMGs strongly emphasized the need to increase their knowledge, and the belief that more precise knowledge of variables such as the age structure and spatial movements of the moose population was essential for positive outcomes. Information and monitoring were regarded as crucial elements of sustainable management, so they strongly encouraged use of monitoring methods to increase their knowledge of the local conditions and variations within the MMA:

"When we make our MMU and MMA plans we try to take in as many facts as we can, so there are no doubts. It's facts that we base it on all the time like Älgobs [moose observations], pellet counts, harvest statistics, age assessment, calf weights, reproduction, browsing pressure and even ÄBIN [browsing inventory]." (Interview 4, landowner representative)

They also developed their own methods, such as building time series data to improve understanding of the way the ecosystem functions in the MMA. Again, the competencies the members brought to the groups were regarded as important components of their work, which also fed into their theory of change and the building of knowledge:

"Then we have a guy, a hunter representative on our board, who keeps incredible statistics on everything and among other things age assessment... been doing it for about 20 years... It's a thing that's very valuable and we're probably quite unique with here I think... that we have a long history of this. So that's how we go about it then." (Interview 4, landowner representative)

Other MMGs emphasized the ecosystem approach as a way to achieve their goals. More precisely, they saw multi-species management as crucial for positive outcomes. This was particularly evident for MMGs in areas with a combination of multiple ungulate species. Here, an ecosystem perspective was seen as important, because in order to manage "a great mix of everything", they had to consider the interactions among species in their management plans. These MMGs had realized the need to attend to the ecological dynamics, and hence adopted a holistic theory of change: 
"... we have actually, both internally and externally, discussed holism in a completely different way than in areas where it's been decided to just manage moose, which is our formal assignment. We have a holistic perspective when we formulate our management plans, we have it in the discussions with the CAB and you could say that it's heavily reflected in our discussions with the MMUs." (Interview 2, landowner representative)

Lastly, some MMGs most strongly emphasized local adaptation. These groups tended to rely on the different experiences and competencies of the group members or MMUs to build their capacity to adapt to local conditions. This was particularly important if the MMA was geographically vast and remoteness required specific local knowledge:

"Because it's such a large area, you have to work in a slightly different way ... it's important to include people who have local knowledge of all parts of the management area. Because we have large management areas, we all know the management area generally, but when it comes to the details, it's usually someone who knows better than anyone else and then you have to trust that person more." (Interview 5, landowner representative)

Local adaptation seemed to be a substantial part of several MMGs' theory of change, but they differed in the strategy for its formal incorporation in procedural arrangements. The described processes could be classified as top-down or bottom-up. In the top-down approach, the MMGs decided overarching goals for the area, but created room for local adaptation by maintaining a certain flexibility in the alignment with MMU goals.

"There you have to have a feeling for the area, so you know in this part of the management area we have a higher moose population than in this other part. So, these two MMU plans cannot both harmonize or be exactly the same as the management plan, rather here it must be higher and here it may have to be lower than in the management plan." (Interview 5, landowner representative)

Furthermore, they tried to maintain an open dialogue with the MMUs to enable adaptation to local changes and establish practical solutions such as the quick relocation of quotas during the ongoing hunting season.

In the bottom-up approach, MMGs placed responsibility and trust in the MMUs to have adequate local knowledge to develop suitable goals and plans for their units. They saw the management plan of the MMA rather as the sum of locally adapted goals. Interviewees expressed how they tried to support MMUs with the development of new tools, as they had identified limitations in the usefulness of certain monitoring methods on a local scale:

"We need better tools. We work a lot with local inventories, pellet counts, browsing inventories, and we're trying to get an App, to collect data in the field... With all due respect to ÄBIN, it describes the management area overall and it's very, very difficult for people out in the MMUs to absorb that information. They say, 'No, I don't recognize my home area when I read ÄBIN'. But if they've done this browsing inventory we're trying to introduce, they look with completely different eyes in the forest." (Interview 3, landowner representative)

Regardless of whether MMGs focused on generation of precise knowledge, an ecosystem approach or local adaptation, their interviewed representatives all expressed commitment to their respective theory of change. This was reinforced by the success they experienced, and confidence in their working procedures was manifested in maintenance of their strategy even if it was less successful than hoped in some years. Many of them highlighted how they focused on creating long-lasting trends, rather than over-adapting in the face of unexpected natural variations.

“We don't just look at developments over a year, we look at trends and in which direction we're heading. Because you also have to work long-term [...] when working with nature, there are both variations and annual variability. Like, it's probably part of life that we'll have to live with that we have some variations. But the important thing is that we stick to the long-term goal and don't tinker with it." (Interview 3, landowner representative) 


\subsubsection{Procedural Arrangements}

Procedural and institutional arrangements varied among the 'good examples' and were tailored to the MMAs' respective theory of change, context setting and network structure (Figure 4). Depending on the variation in number of MMUs and License areas (see Figure 2), the MMGs developed different procedures to allow for principled engagement across governance levels. In small areas with few MMUs, the MMU chairperson might also be a MMG representative. This dual role could simplify goal alignment and communication, but it is not a feasible arrangement for large areas with high numbers of MMUs and License areas. In these cases, the interviewees described different procedures to enable inclusion of all views in the management process and better facilitation of goal alignment, for example, a mentorship program in which MMG members were assigned responsibility for collaboration with certain MMUs within their area.

“... an important factor was the introduction of a mentoring system in which each member of the MMG has responsibility for one or a few management units to especially assist them, follow them, and help them with different things. I don't think that's been bad at all really. And then we compile this information in the group, and if someone has a little difficulty fixing it, we help out all the time, so we've been a good working group in the management group, I think we've been successful in that way too, in fact." (Interview 2, hunter representative)

Some of the MMGs had implemented communication strategies to receive input from all the MMUs and License areas via questionnaires, which "can come from each hunting team, then it's even better, and you get statistics on what they think" (Interview 4, hunter representative). Some MMGs hosted larger meetings with representatives from all hunting teams or opened their internal MMG meetings to increase MMUs' involvement and influence in the management.

The usefulness of digital communication via email, or Apps (existing or newly created), to reach larger numbers of actors simultaneously and quickly was mentioned by several interviewees. This mode of communication also provided the MMGs with possibilities to collect information regarding local ecological conditions (e.g., monitoring data or occurrence of browsing damage).

In conclusion, all the 'good examples' displayed innovation and adaptation in their collaboration dynamics to find solutions that worked in their contextual settings. Furthermore, they reflected on their role within the system, and both their communication and collaboration, to further improve their performance. This might entail trying out new ways to communicate in order to create interest and understanding from the MMUs, or to reflect on the limitation of existing tools and ways to improve them.

"I feel that we can get even better at this with local inventories and the fun thing is that there's a lot of interest in it. So, we feel very strong support for this when we're out, not least after the recent collaboration meeting we had. So many people have come back and discussed this and wanted to get us to their local collaboration meetings. Plus, I feel there's a surprisingly large attendance at our education courses. And yet, I feel that we can't really deliver everything, because we don't have this inventory App ready and we don't have everything to present really well and clearly. But this is still developing." (Interview 3, landowner representative)

The interviewees' comments also showed that the MMGs strived to identify knowledge gaps and actively sought support from researchers or practitioners in the field. Lastly, many of them expressed thoughts about how to safeguard the longevity of the system, as they were aware that it demanded effort and commitment from all participants.

\section{Discussion}

As already described, the overarching goals of the recently introduced CGR are to maintain a high-quality moose population while reducing its negative consequences for forestry and conflicts, among actors. Our previous research showed the importance of 
multi-level collaboration in this arrangement $[27,28]$. From the literature, we know that making collaborative governance work in wicked problem contexts and across multiple administrative levels is difficult, due to a high degree of societal complexity $[14,22,30,33]$. In our study, we departed from the Integrative Framework for Collaborative Governance [12], to explore how the elements of principled engagement, shared motivation and capacity for joint action are interconnected, both within and among governance levels of Swedish moose management. Our interviews with representatives of 'good examples' of MMGs showed that these three elements are virtuously connected through social capital, shared theories of change, leadership and procedural arrangements (Figure 5).

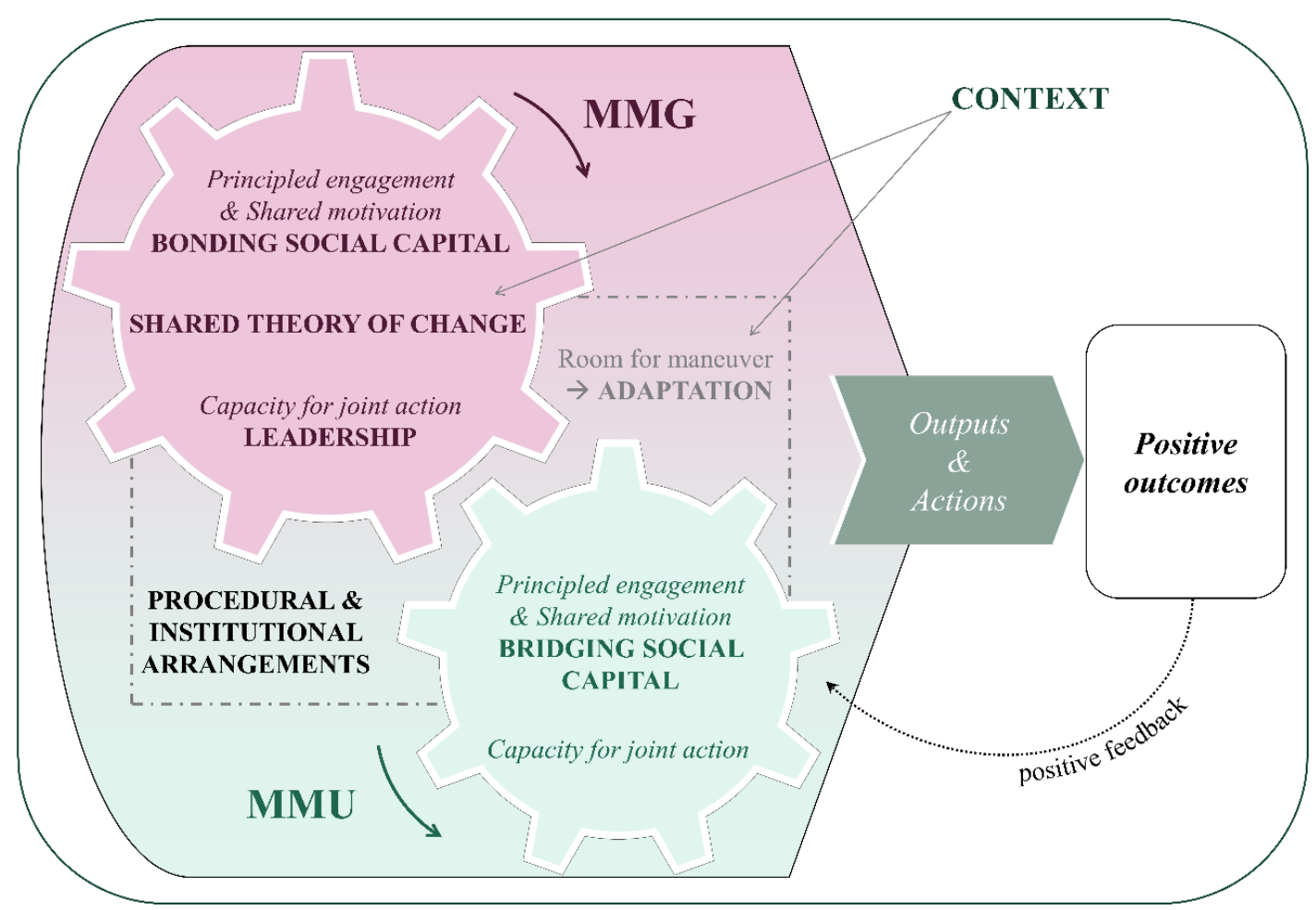

Figure 5. Multi-level collaboration dynamics discovered within the 'good examples'. Moose Management Groups' (MMG) collaboration dynamics (pink) influence collaboration dynamics with Moose Management Units (MMU, green), as the room for maneuver allows MMGs to implement well-adapted procedural and institutional arrangements that create principled engagement, shared motivation and capacity for joint action among the two governance levels.

Overall, we found evidence of locally adapted and well-functioning collaboration dynamics within all the chosen 'good examples'. We identified consistency in the interviewees' descriptions of how existing social networks and previous experience facilitated their initial deliberations within the groups. It further helped them to acknowledge the interdependence of hunting and landowner interests and the importance of trust and communication in their collaborative work. As a result, groups display high bonding social capital, that is, they trust each other's abilities and competencies, and utilize members' expertise in making and improving the quality of their decisions. The interviewees' responses also strongly indicate that continuity, in terms of keeping the groups as intact as possible, helps building commitment to the process. The link between social capital and continuity in group constellations has also been shown elsewhere to be an important factor in multi-level adaptive governance regimes [51]. The presence of principled engagement and shared motivation within the selected MMGs contributed to their ability to formulate a shared theory of change. This can be understood as clear evidence of collaborative social learning. Interviewees from all six groups share the understanding that awareness of the socio-ecological context and challenges it creates is crucial. This has allowed the groups to develop a particular mindset to jointly discover and define their respective theories of 
change and to find the matching set of tactics or techniques. The focus on long-term trends rather than occasional deviations often enables reframing of the groups' purpose from merely solving a problem to consideration of how the MMGs and MMUs can potentially improve their specific situations. Hence, improvements become desirable and possible through collective action.

As previously mentioned, the amended policy for moose management does not specify exactly how collaboration among the governance levels should be realized. This has created discretion, or room for maneuver, in the design of procedural arrangements. The studied 'good examples' actively exploited this discretionary power in creating institutional arrangements that enabled them to reach their goals. It also contributed to the creation of room for different types of leadership styles. While interviewees described quite directly a variety of leadership roles that they commonly fulfil, such as conveners, facilitators and mediators, the most prominent was their ability to act as initiating leaders or 'process champions'. The importance of this kind of leadership for successful collaborative governance has previously been identified in the literature. Characteristic features are dedication, acknowledgement of contextual challenges and use of social networks and trustworthiness to generate 'motivational force' for the CGR [12,51-53]. Accordingly, the 'good examples' of MMGs constructed formal and informal rules and protocols that they consider suitable for the social-ecological context, the existing social networks (i.e., number of MMUs and License areas) and their theory of change. They showed flexibility and creativity in their use and development of locally adapted management tools and communication strategies. In some of the cases, this emanated from their historical and social ties to the areas and in others, from the need to delegate tasks to lower levels due to the size of the area. Overall, it enabled them to implement effective institutional arrangements. This in turn reinforces the establishment of principled engagement among levels, or (more specifically) MMGs' collective activity with MMUs in the discovery, definition, deliberation upon and determination of a common understanding and plan of action (Figure 5). This can create shared motivation among governance levels and strengthen bridging social capital between MMUs and MMGs. Thus, good examples show a previously described effect of local leadership, leading to improved institutional fit and multi-level collaboration [51,53-56]. Ultimately, the improved relational and structural aspects of multi-level collaboration increase the capacity for joint action within the MMA. Positive outcomes, such as confirmed trust from MMUs and achievement of ecological goals, has provided positive feedback for the selected groups, reinforced their shared theory of change, promoted the implementation of procedures and strengthened their collaboration (Figure 5).

In summary, the links we discovered among principled engagement, shared motivation and capacity for joint action (Figure 5) illustrate what could be described as a positive feedback link from within-level collaboration dynamics to between-level dynamics. MMG representatives played a central role in the design and adaptation of institutional arrangements between the two governance levels. In the studied cases, the representatives' existing social networks and previous experience allowed them to assume organic leadership. Their reputation and trustworthiness gave them credibility to realize their strategic vision (i.e., theory of change), even if it extended beyond their official mandate. The combination of collaboration-oriented and motivated individuals with carefully tailored procedural arrangements contributed to the strengthening of social capital and collective action within and among levels. As, in this study, we focused solely on the perceptions of MMG representatives, additional studies on the MMU level and synchronous studies of multiple governance levels are necessary to substantiate our findings on feedback links from within-level collaboration dynamics to between-level dynamics. Furthermore, our study raises the question of if negative feedback links on multi-level collaboration might exist in cases with poor collaboration dynamics within MMGs.

Our study also indicates a link between process performance and productivity performance of CGRs [32], as we selected the cases partly based on their good ecological outcomes (i.e., reaching harvest quotas and reducing negative impacts). This suggests that 
robust collaboration dynamics within and across governance levels might have positive effects on outputs and outcomes. To test this relationship further, more cases, including those with dysfunctional collaboration dynamics and/or those struggling to achieve desired outcomes, need to be studied for the presence or absence of our identified success factors.

From a policy perspective, our findings raise questions about how the observed good collaboration dynamics, social learning processes and individual-based attributes can be promoted, especially as previous studies detected limitations in linking and bridging social capital between governance levels [28]. While several of the described working procedures (e.g., the mentorship program, and use of digital communication) could easily be transferred to other settings, aspects such as shared learning process, leadership skills and specific representatives' social roles within a community cannot be artificially created. This makes the CGR highly dependent on the involved individuals. Furthermore, this implies that changes in representatives or key individuals might influence collaboration dynamics and ultimately, outcomes. The interviewees touched upon this by describing how the exchange of certain persons influenced the relationships among levels, and questioning who will take over their roles if they resign. MMG representatives are suggested by interest organizations, and little is known of their selection strategies or procedures, and to what extent the needs of the existing MMG are considered. However, MMG representatives often receive training through their respective interest organizations or CABs, and a focus on communication and leadership skills could help groups to reflect on the composition of roles and tasks that are needed within an effective and efficient MMG. Our findings also highlighted the importance of social learning as it resulted in procedural arrangements that were well-adapted to the local social-ecological context. This raises the question of how future policy reforms can utilize the generated knowledge from these learning processes and acknowledge the demand for regionally and locally adapted institutions.

\section{Conclusions}

In a search for 'good examples', we sampled a list of 15 MMGs and found that several performed better than the national average in terms of both social and ecological outcome measures. Six of these MMGs were selected for in-depth studies to explore and compare the collaboration dynamics and how these dynamics were reflected in concrete situations. In particular, we aimed at exploring the central elements (see Figure 1) that may explain why our 'good examples' have achieved positive outcomes. Such understanding may facilitate formulation of more sustainable approaches for the management of common resources, avoidance of problematic measures and establishment of foundations for policy reforms [29]. Hence, our study of six MMGs provides practical insights into working procedures that can be adapted by other actors in the system, contribute to social and institutional learning and ultimately improve the functionality of the moose management system per se. From a theoretical perspective, our study substantiates the importance of social capital, leadership and adaptation to social and ecological context factors. We hope our findings of potential feedback links from within-level collaboration dynamics to between-level collaboration will encourage the extended use of the IFCG in multilevel settings and open up for future discussions about potential feedback loops within multi-level collaborative governance regimes.

Author Contributions: Conceptualization, S.D., G.E. and C.S.; Formal analysis, S.D., A.S.-L. and C.S.; Funding acquisition, A.S.-L., M.J., G.E. and C.S.; Methodology, S.D., G.E. and C.S.; Visualization, S.D.; Writing-original draft, S.D., A.S.-L. and C.S.; Writing—review and editing, M.J. and G.E. All authors have read and agreed to the published version of the manuscript.

Funding: This research was funded by the Swedish Environmental Protection Agency's Wildlife Management Fund (Naturvårdsverket Viltvårdsfonden, grant number 802-0161-15), the Swedish Association for Hunting and Wildlife Management (Svenska Jägareförbundet, grant number 5871/2018), and the governmental assignment on moose management to SLU (Regeringsbeslut N2018/04160/FJR, 2018-07-12). 
Institutional Review Board Statement: The study was conducted according to the guidelines of the Declaration of Helsinki and the General Data Protection Regulation (GDPR, EU, 2016/679). As the data collection did not include any sensitive personal data (i.e., data revealing racial or ethnic origin, political opinions, religious or philosophical beliefs, trade union membership, genetic data, biometric data for the purpose of uniquely identifying a natural person, data concerning health or data concerning a natural person's sex life or sexual orientation), no ethical approval was required according to the Swedish Act concerning the Ethical Review of Research Involving Humans (Lagen om etikprövning, SFS 2003:460). The data collection was registered according to the data protection regulation with the universities Data Protection Officer. In addition, we applied the highest standards to safeguard participants' privacy and rights, and followed recommendations for good research practice (Swedish Research Council, 2017).

Informed Consent Statement: Informed consent was obtained from all subjects involved in the study.

Data Availability Statement: The data are not publicly available to ethical and privacy restrictions.

Acknowledgments: We thank all the participants who contributed valuable insights via the interviews or answering the survey. We also thank our research assistants for entering data about management plans and transcription of recorded interviews.

Conflicts of Interest: The authors declare no conflict of interest. The funders had no role in the design of the study; in the collection, analyses, or interpretation of data; in the writing of the manuscript, or in the decision to publish the results.

\section{References}

1. Liberg, O.; Bergstrom, R.; Kindberg, J.; von Essen, H. Ungulates and their management in Sweden. In European Ungulates and Their Management in the 21st Century; Apollonio, M., Andersen, O., Putman, R., Eds.; Cambridge University Press: Cambridge, UK, 2010; p. 618.

2. Danell, K.; Bergström, R.; Mattsson, L.; Sörlin, S. Jaktens Historia i Sverige: Vilt-Människa-Samhälle-Kultur; Liber AB: Stockholm, Sweden, 2016.

3. Sandström, C.; Wennberg Di Gasper, S.; Öhman, K. Conflict resolution through ecosystem-based management: The case of Swedish moose management. Int. J. Commons 2013, 7, 549-570. [CrossRef]

4. Kardell, Ö. Swedish Forestry, Forest Pasture Grazing by Livestock, and Game Browsing Pressure Since 1900. Environ. Hist. 2016, 22, 561-587. [CrossRef]

5. Boman, M.; Mattsson, L.; Ericsson, G.; Kriström, B. Moose Hunting Values in Sweden Now and Two Decades Ago: The Swedish Hunters Revisited. Environ. Resour. Econ. 2011, 50, 515-530. [CrossRef]

6. Wallgren, M.; Bergström, R.; Bergqvist, G.; Olsson, M. Spatial distribution of browsing and tree damage by moose in young pine forests, with implications for the forest industry. Ecol. Manag. 2013, 305, 229-238. [CrossRef]

7. Månsson, J.; Kalén, C.; Kjellander, P.; Andrén, H.; Smith, H. Quantitative estimates of tree species selectivity by moose (Alces alces) in a forest landscape. Scand. J. For. Res. 2007, 22, 407-414. [CrossRef]

8. Uthållig Älgförvatlning i Samverkan; SOU 2009:54; Fritzes Offentliga Publikationer: Stockholm, Sweden, 2009 ; p. 218.

9. Wennberg Di Gasper, S. Natural Resource Management in an Institutional Disorder: The Development of Adaptive Co-Management Systems of Moose in Sweden; Luleå University of Technology: Luleå, Sweden, 2008.

10. CBD SBSTTA. Convention on Biological Diversity: Recommendation V/10 Ecosystem approach-Further conceptual elaboration. In Proceedings of the 5th Subsidiary Body of Scientific and Technological Advice Meeting, Montreal, QC, Canada, 31 January-4 February 2000.

11. Älgförvaltningen; 2009/10:239; Fritzes Offentliga Publikationer: Stockholm, Sweden; p. 84.

12. Emerson, K.; Nabatchi, T. Collaborative Governance Regimes; Georgetown University Press: Washington, DC, USA, $2015 ;$ p. 264.

13. Jager, N.W.; Newig, J.; Challies, E.; Kochskämper, E. Pathways to Implementation: Evidence on How Participation in Environmental Governance Impacts on Environmental Outcomes. J. Public Adm. Res. Theory 2019. [CrossRef]

14. Bodin, Ö. Collaborative environmental governance: Achieving collective action in social-ecological systems. Science 2017, 357. [CrossRef] [PubMed]

15. Koontz, T.M.; Jager, N.W.; Newig, J. Assessing Collaborative Conservation: A Case Survey of Output, Outcome, and Impact Measures Used in the Empirical Literature. Soc. Nat. Resour. 2019, 1-20. [CrossRef]

16. Sjölander-Lindqvist, A.; Sandström, C. Shaking Hands: Balancing Tensions in the Swedish Forested Landscape. Conserv. Soc. 2019, 17, 319-330. [CrossRef]

17. Bjärstig, T.; Sandström, C.; Lindqvist, S.; Kvastegård, E. Partnerships implementing ecosystem-based moose management in Sweden. Int. J. Biodivers. Sci. Ecosyst. Serv. Manag. 2014, 10, 228-239. [CrossRef]

18. Dressel, S.; Ericsson, G.; Sandström, C. Mapping social-ecological systems to understand the challenges underlying wildlife management. Environ. Sci. Policy 2018, 84, 105-112. [CrossRef] 
19. Uppföljning av Mål Inom Älgförvaltningen—Redovisning av Regeringsuppdrag; Swedish Environmental Protection Agency: Stockholm, Sweden, 2018; p. 59.

20. Redovisning av Regeringsuppdrag om Älgförvaltning; Swedish Environmental Protection Agency: Stockholm, Sweden, $2015 ;$ p. 21.

21. Ansell, C.; Gash, A. Collaborative governance in theory and practice. J. Public Adm. Res. Theory 2008, 18, 543-571. [CrossRef]

22. Clement, S.; Guerrero Gonzalez, A.; Wyborn, C. Understanding Effectiveness in its Broader Context: Assessing Case Study Methodologies for Evaluating Collaborative Conservation Governance. Soc. Nat. Resour. 2019, 1-22. [CrossRef]

23. Newig, J.; Challies, E.; Jager, N.W.; Kochskaemper, E.; Adzersen, A. The Environmental Performance of Participatory and Collaborative Governance: A Framework of Causal Mechanisms. Policy Stud. J. 2018, 46, 269-297. [CrossRef] [PubMed]

24. Biddle, J.C.; Koontz, T.M. Goal specificity: A proxy measure for improvements in environmental outcomes in collaborative governance. J. Environ. Manag. 2014, 145, 268-276. [CrossRef]

25. Ostrom, E. A General Framework for Analyzing Sustainability of Social-Ecological Systems. Science 2009, 325, 419-422. [CrossRef]

26. Koontz, T.M.; Newig, J. From Planning to Implementation: Top-Down and Bottom-Up Approaches for Collaborative Watershed Management. Policy Stud. J. 2014, 42, 416-442. [CrossRef]

27. Dressel, S.; Ericsson, G.; Johansson, M.; Kalén, C.; Pfeffer, S.E.; Sandström, C. Evaluating the outcomes of collaborative wildlife governance: The role of social-ecological system context and collaboration dynamics. Land Use Policy 2020, 99, 105028. [CrossRef]

28. Dressel, S.; Johansson, M.; Ericsson, G.; Sandström, C. Perceived adaptive capacity within a multi-level governance setting: The role of bonding, bridging, and linking social capital. Environ. Sci. Policy 2020, 104, 88-97. [CrossRef]

29. Pahl-Wostl, C. A conceptual framework for analysing adaptive capacity and multi-level learning processes in resource governance regimes. Glob. Environ. Chang. 2009, 19, 354-365. [CrossRef]

30. Berkes, F. Environmental Governance for the Anthropocene? Social-Ecological Systems, Resilience, and Collaborative Learning. Sustainability 2017, 9, 1232. [CrossRef]

31. Bodin, Ö.; Sandström, A.; Crona, B. Collaborative Networks for Effective Ecosystem-Based Management: A Set of Working Hypotheses. Policy Stud. J. 2016. [CrossRef]

32. Emerson, K.; Nabatchi, T. Evaluating the Productivity of Collaborative Governance Regimes: A Performance Matrix. Public Perform. Manag. Rev. 2015, 38, 717-747. [CrossRef]

33. Newig, J.; Fritsch, O. Environmental governance: Participatory, multi-level and effective? Environ. Policy Gov. 2009, 19, 197-214. [CrossRef]

34. Agrawal, A. Environmentality: Technologies of Government and the Making of Subjects; Duke University Press: Durham, NC, USA, $2005 ;$ p. 344.

35. Sjölander-Lindqvist, A.; Johansson, M.; Sandström, C. Individual and collective responses to large carnivore management: The roles of trust, representation, knowledge spheres, communication and leadership. Wildl. Biol. 2015, 21, 175-185. [CrossRef]

36. Sjölander-Lindqvist, A.; Risvoll, C.; Kaarhus, R.; Lundberg, A.-K.; Sandström, C. Knowledge claims and struggles in decentralized large carnivore governance: Insights from Norway and Sweden. Front. Ecol. Evol. 2020, 8. [CrossRef]

37. Conley, A.; Moote, M.A. Evaluating collaborative natural resource management. Soc. Nat. Resour. 2003, 16, 371-386. [CrossRef]

38. Emerson, K.; Gerlak, A.K. Adaptation in Collaborative Governance Regimes. Environ. Manag. 2014, 54, 768-781. [CrossRef] [PubMed]

39. Lebel, L.; Anderies, J.M.; Campbell, B.; Folke, C.; Hatfield-Dodds, S.; Hughes, T.P.; Wilson, J. Governance and the Capacity to Manage Resilience in Regional Social-Ecological Systems. Ecol. Soc. 2006, 11, 19. Available online: http:/ / www.ecologyandsociety. org/vol11/iss1/art19/. [CrossRef]

40. Reed, M.S.; Evely, A.C.; Cundill, G.; Fazey, I.; Glass, J.; Laing, A.; Newig, J.; Parrish, B.; Prell, C.; Raymond, C.; et al. What is Social Learning? Ecol. Soc. 2010, 15. [CrossRef]

41. Pelling, M.; High, C. Understanding adaptation: What can social capital offer assessments of adaptive capacity? Glob. Environ. Change 2005, 15, 308-319. [CrossRef]

42. Paldam, M. Social Capital: One or Many? Definition and Measurement. J. Econ. Surv. 2000, 14, 629-653. [CrossRef]

43. Brondizio, E.S.; Ostrom, E.; Young, O.R. Connectivity and the Governance of Multilevel Social-Ecological Systems: The Role of Social Capital. Annu. Rev. Environ. Resour. 2009, 34, 253-278. [CrossRef]

44. Nenadovic, M.; Epstein, G. The relationship of social capital and fishers' participation in multi-level governance arrangements. Environ. Sci. Policy 2016, 61, 77-86. [CrossRef]

45. Grafton, R.Q. Social capital and fisheries governance. Ocean Coast. Manag. 2005, 48, 753-766. [CrossRef]

46. Om Jakt och Viltvård; 1991/92:9; Fritzes Offentliga Publikationer: Stockholm, Sweden, 1991; p. 274.

47. Dressel, S. Social-Ecological Performance of Collaborative Wildlife Governance: The Case of Swedish Moose Management. Doctoral Thesis, Swedish University of Agricultural Sciences, Umeå, Sweden, 2020.

48. Robson, C. Real World Research, 3rd ed.; John Wiley \& Sons Ltd.: Chichester, UK, 2011; p. 586.

49. Good Research Practice; Swedish Research Council: Stockholm, Sweden, 2017.

50. Creswell, J.W.; Miller, D.L. Determining Validity in Qualitative Inquiry. Theory Pract. 2000, 39, 124-130. [CrossRef]

51. Sharma-Wallace, L.; Velarde, S.J.; Wreford, A. Adaptive governance good practice: Show me the evidence! J. Environ. Manag. 2018, 222, 174-184. [CrossRef]

52. Yaffee, S.L. Collaboration Strategies for Managing Animal Migrations: Insights from the History of Ecosystem-Based Management. Environ. Law 2011, 41, 655. 
53. Olsson, P.; Folke, C.; Berkes, F. Adaptive Comanagement for Building Resilience in Social-Ecological Systems. Environ. Manag. 2004, 34, 75-90. [CrossRef]

54. Galaz, V.; Olsson, P.; Hahn, T.; Folke, C.; Svedin, U. The problem of fit among biophysical systems, environmental and resource regimes, and broader governance systems: Insights and emerging challenges. In Institutions and Environmental Change-Principal Findings, Applications, and Research Frontiers; Young, O.R., King, L.A., Schröder, H., Eds.; The MIT Press: Cambridge, MA, USA, 2008; pp. 147-182. [CrossRef]

55. Butler, J.R.A.; Young, J.C.; McMyn, I.A.G.; Leyshon, B.; Graham, I.M.; Walker, I.; Baxter, J.M.; Dodd, J.; Warburton, C. Evaluating adaptive co-management as conservation conflict resolution: Learning from seals and salmon. J. Environ. Manag. 2015, 160, 212-225. [CrossRef] [PubMed]

56. Stöhr, C.; Lundholm, C.; Crona, B.; Chabay, I. Stakeholder participation and sustainable fisheries: An integrative framework for assessing adaptive comanagement processes. Ecol. Soc. 2014, 19. [CrossRef] 